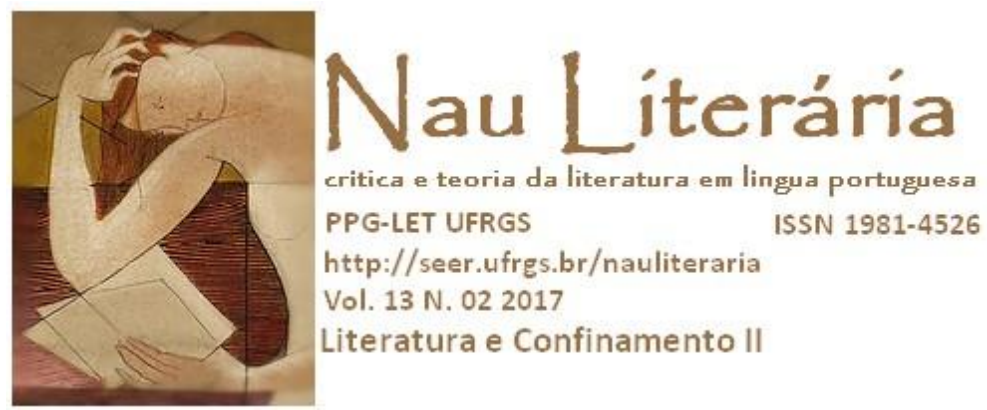

\title{
Lídia Jorge: a trapaça no feminino
}

Mônica Figueiredo

Resumo: A partir da leitura do conto "Marido", de Lídia Jorge (1997), este texto pretende investigar as formas de inscrição da subjetividade feminina na narrativa portuguesa contemporânea. Longe de querer problematizar a possível existência de um "sexo" para os textos, o que aqui se deseja é antes recuperar certa tradição responsável pela fixação da imagem da mulher na literatura ocidental e pô-la em xeque através do doloroso percurso inscrito pela "confinada" Lúcia, personagem construída pela dicção "gaguejante" da fícção de Lídia Jorge. Para tanto, partirei da releitura da figura de Medeia, feita pelo texto teatral de Chico Buarque de Holanda e Paulo Pontes: o emblemático Gota d'água (1975). Contrapondo tradição e ruptura, o texto de Lídia Jorge parece corroborar com a assertiva de Kristeva, quando esta afirma que "o divino nas mulheres corresponde ao seu masoquismo", criando assim uma outra forma de resistência à violência que incide, historicamente, sobre o corpo feminino.

Palavras-chave: Lídia Jorge; Literatura Portuguesa; Feminino; História.

ABSTRACT: By reading Lídia Jorge's tale, "Marido"(1997), this text aims to investigate the forms of female subjectivity inscriptions in the contemporary portuguese narrative. Far from willing to problematize the possible existence of a genre for the texts, what is wished by this work is to recover a certain tradition responsible for the fixation of the woman image in the Western literature, and to put it to a stop through the painful road pointed by the "confined" Lúcia, a character builded by "stuttering" Lídia Jorge's fiction. Because of that, I'll start from Chico Buarque de Holanda and Paulo Ponte's theatrical text re-reading of the Medeia figure: the emblematic "Gota d'água" (1975). Opposing tradition and rupture, Lidia Jorge's text seems to support Kristeva's words, when she states that "women's deity corresponds to their masochism", creating a whole other form of withstanding the historical violence against women's' bodies.

KEYWORDS: Lídia Jorge; Portuguese Literature; Women; History.

Já lhe dei meu corpo, minha alegria.

Já estanquei meu sangue quando fervia.

Olha a voz que me resta,

Olha a veia que salta,

Olha a gota que falta

Pro desfecho da festa, por favor.

Deixe em paz meu coração,

Que ele é um pote até aqui de mágoa,

E qualquer desatenção, faça não!

Pode ser a gota d'água. 
O texto que me serve de epígrafe é a letra de uma canção composta pelo músico brasileiro Chico Buarque de Holanda, em 1975. Naquele ano, em plena ditadura militar, estreava no Teatro Tereza Raquel, no Rio de Janeiro, a peça Gota d'água, resultado da parceria do já então reconhecido compositor com um de nossos melhores dramaturgos, Paulo Pontes ${ }^{1}$. A montagem atualizava a tragédia clássica de Eurípedes, Medeia, trazendo-a para um subúrbio carioca, onde a ira da personagem grega era revivida por uma Joana, mulher madura, exaurida pelo trabalho, além de sobrevivente a tempos de dura opressão. No texto brasileiro, Joana era perdidamente apaixonada por um Jasão, agora malandro e compositor de sambas, que vivia seu momento glorioso, graças ao sucesso conseguido por uma canção de sua autoria, chamada Gota d'água. Ao abandonar o primeiro marido para viver com um rapaz dez anos mais novo, Joana faz de Jasão o seu mundo, dando a ele os seus melhores anos, o seu corpo, o seu trabalho e dois filhos. A peça começa no momento da ascensão de Jasão, que desejava deixar para trás o seu passado — e com ele Joana - , para iniciar uma vida nova junto de Alma. A moça era filha de um poderoso local, Creonte, proprietário que vivia da exploração imobiliária, mantendo sob jugo todos os moradores e, entre eles, uma Joana que, corroída pelo ressentimento gerado pelo abandono do amante, só pensava em se vingar.

Fingindo submeter-se às ameaças de Creonte e ao desprezo de Jasão, Joana simula uma reconciliação, mandando à noiva doces envenenados de presente no dia do casamento. A prenda mortal é levada pelas mãos dos dois filhos de Jasão, que são vexatoriamente expulsos da festa, tendo de trazer de volta o presente virulento que não fora aceito. Ao saber que seu plano não dera certo e que Jasão nada fizera para evitar a humilhação a que foram expostos seus filhos, Joana surta e pede que a vizinha lhe deixe sozinha com os meninos, dizendo: "Tá bem, mas me deixa comigo um pouco que tá fazendo um barulho de louco na minha cabeça e eu preciso paz" (1975, p. 98). Sem entender por que não conseguiu concretizar seu plano de vingança, Joana discute com Deus (na peça, propositalmente representado por uma instância que reúne: o bem e o mal, as referências católicas e africanas, a experiência popular e a cultura clássica), imaginando-se injustamente abandonada pelas divindades com que sempre contou: "a Virgem e o Padre Eterno, todos os santos, anjos do céu e do inferno [...], [e] todos os orixás do Olimpo" (1975, p. 67).

\footnotetext{
${ }^{1}$ Os versos citados são da canção "Gota d'água" que dá nome ao espetáculo. O texto teatral é inspirado numa adaptação televisiva feita por Oduvaldo Viana Filho. A peça ganhou o Prêmio Molière de melhor texto teatral, em 1975.
} 
Exausta diante do precipício em que se colocou, atada a um homem que lhe reforçava a condição de abandono, Joana decide dar a provar aos filhos e a si mesma do próprio veneno, aposta cega que cria no depois da morte um espaço de redenção, um lá mágico, onde "ninguém briga, lá ninguém espera, ninguém empurra ninguém" (1975, p. 99). Serão os corpos mortos dela e dos filhos a sua efetiva vingança, o caminho de ultrapassagem que a livra da cadeia do ressentimento. Seguindo uma enviesada lógica de libertação, Joana conclui: "Eu compreendi que o sofrimento de conviver com a tragédia todo dia é pior que a morte por envenenamento" (1975, p. 73). Estamos diante, portanto, de uma personagem que se sabe em meio a uma tragédia, tragédia que lhe envenena os dias e que aqui ouso chamar de ressentimento. Recuperando o mito clássico de Medeia e, no mesmo sentido, mantendo estreita correlação com o texto de Eurípedes, Joana é dona de um peculiar ponto de vista que vê na vingança a forma fatal de restabelecer o que entende por justiça.

De Medeia, a bárbara feiticeira que afrontou o poder patriarcal sob o qual se ergueu o mundo grego, à Joana e sua estreita condição de mulher oprimida no Brasil ditatorial dos anos 70, uma saga de mulheres deixou registro em ficção. Foi pensando nelas, nas que ousaram vencer o lugar da repressão e do desvalimento através do despudor com que usaram o ódio habitualmente, força de ação tão masculina! - é que me lembrei de Lúcia, a porteira agredida pela violência de um casamento, criada pelas linhas de Lídia Jorge no conto "Marido"2.

Poucas vezes a leitura de um texto me causou tão grande incômodo. Deixe-se registrado que Lídia Jorge nunca foi - e para nossa sorte jamais o será! - exemplo de cômoda leitura, mas, mesmo levando isto em conta, percorrer esta narrativa breve doeu mais do que o habitual. Num primeiro momento, o enredo veio como melhor justificativa para meu mal-estar, afinal a história de uma mulher acuada entre gaiolas de pombos, num terraço de um prédio anônimo, cotidianamente violentada pela rudeza bêbada de um marido, por si só, já caberia como explicação razoável para a inquieta sensação que acompanhou toda a leitura. No entanto, o final do conto retirou de mim o resto de conforto e a violência extremada que reveste o assassinato/suicídio da personagem me roubou qualquer possibilidade de sossego. A cena de um

${ }^{2}$ A edição aqui usada é: Jorge, Lídia. "Marido". In: Melo, João de (org.). Antologia do conto português. Lisboa: Publicações D. Quixote, 2002, p. 483-492. Para as citações do texto, utilizarei a abreviação $M$, seguida do número da página. 
corpo feminino a correr em chamas, clamando pela Virgem Maria, ou melhor, por "Regina", pareceu-me macabro demais até mesmo para uma personagem de Lídia Jorge.

No fundo, o inusitado da cena atingiu-me em cheio, porque me recusei a crer que um conto de estrutura narrativa tão refinada estivesse somente a serviço da denúncia da situação de constrangimento e de brutalidade a que estão sujeitas as mulheres em nossa contemporaneidade. Se meninas são estupradas em ônibus na Índia; se corpos femininos são vendidos como mercadoria pelas redes de tráfico humano; se mulheres são assassinadas simplesmente porque não se "comportam bem" aos olhos de um poder patriarcal que ainda governa; se garotas são mutiladas em sua sexualidade pelas mãos de seus familiares; muito desta violência surge cifrada, de forma gaguejante, na obra ficcional de uma escritora que intui que o melhor discurso para “dizer" a violência é aquele que desvela a presença do silêncio aterrador que a envolve e, assim, a faz parecer "normal" porque a "domestica". Não será gratuita a presença insistente da imagem da casa nos livros de Lídia Jorge: é na casa, espaço daquilo que é mais íntimo, que a violência brota, atingindo de maneira preferencial os corpos femininos.

Tenho consciência de que aqui abro espaço para outra linha de leitura, ao avançar na contramão de alguns estudos que cuidadosamente se debruçaram sobre este conto, (ou mesmo sobre todo o livro em que ele aparece incluso $^{3}$ ), na tentativa de ressaltar a referencialidade histórica de que a ficção se vale, posicionando a obra de Lídia Jorge dentro de um eixo temático que elege a problematização da condição feminina como tema. Minha intenção não é desdizer a linha crítica que aponta "Marido" como um exemplo de texto socialmente engajado, que se vale da ficção para reavaliar a experiência feminina neste novo milênio. Contudo, acredito que uma análise como esta não basta para dar conta daquilo que escapa, daquilo que excede e que fica a descoberto, por causa da rasura criada pela fala gaguejante e obsessiva da precária Lúcia. Maria Madalena Gonçalves parece concordar comigo, quando sobre o livro afirma:

[...] todas as personagens centrais ao conflito saem dele por via de uma energia psíquica que tem alguma coisa de irracional (uma espécie de pulsão da morte como que a antecipar o próprio desfecho das narrativas) e, ao mesmo tempo, alguma coisa de fantasmático (como se a saída da crise tivesse a ver com a realidade desejada pelo sujeito e não tanto com a realidade vivida por ele). (2000, p. 127)

\footnotetext{
${ }^{3}$ Refiro-me a Marido e outros contos (1997).
} 
Será esta "realidade desejada pelo sujeito" que dotará Lúcia de uma força "sobrehumana", fazendo-a desafiar o destino graças a uma "espécie de hybris" exacerbada, dirigida contra a "sociedade que faz dela uma personagem trágica" (GONÇALVES, 2000, p. 132); ou, por outras palavras, que faz de Lúcia a memória atualizada de gregas medeias e de brasileiras joanas. Não se pode esquecer que a "saída da crise" é um processo "em construção", por isso o conto se abre flagrando a personagem em meio a mais uma oração dirigida à Regina. Ela espera a chegada de seu homem, aterrada pela angústia de outra noite de vergonha, medo e violência. Propositadamente, o conto inicia-se in media res. Neste caso, o recurso é usado para evidenciar a imobilidade que reveste os dias da porteira, repetidos e anônimos como uma interminável ladainha.

A dor de Lúcia é uma dor imposta por um casamento violento do qual ela não pode, ou melhor, não quer sair. A experiência traumática vivida pela porteira a imobiliza no lugar da vítima que, se por um lado a faz experimentar o sofrimento, por outro, a exime das responsabilidades que deveria ter em relação a sua própria integridade física-emocional. Lembrese que assim como a Medeia da mitologia clássica deu vida a um único filho chamado Medo, a personagem de Lídia Jorge construiu um marido-filho a quem nomeou pavor:

De resto, ela escondia o dinheiro onde ele nem sabia, e ele nem lho pedia nem queria ver. Quantos, por contraste, não passavam para as mãos das mulheres nem uma moeda, falsa que fosse. Não o seu marido. Ela é que o vestia, ela é que determinava a comida, ela é que o mandava pôr os pregos, ir buscar os pombos, alimentar os pombos. E ele calado. Os inquilinos não viam isso. $(M$, p. 89$)$

A atenção que Lúcia dedica ao marido está minada pelo ódio, um ódio imenso que a faz "rearrumar" sua "realidade" de forma a poder caber. Neste sentido, a estrutura deste conto é primorosa, porque àquilo que o leitor assiste não passa da falhada tentativa de ficcionalização do "real" dentro do próprio espaço da ficção. Lúcia tenta - rasuradamente - encobrir a aterrorizante "verdade" de seu casamento, valendo-se de uma fala incessante, que procura convencer primeiro a si e só depois ao "outro", seja ele Rex, Regina, os vizinhos, ou, num segundo nível, o leitor. Evitando a responsabilidade que lhe cabe na manutenção de uma ordem de opressão — afinal, não há opressor sem oprimido —, Lúcia desloca a responsabilidade de seus dias para o marido, selando para si uma cadeia de ressentimento. Maria Rita Kehl explica que o ressentido sempre atribui "a um outro a responsabilidade" que lhe faz sofrer, ou seja ele cria: 
Um outro a quem delegamos, em um momento anterior, o poder de decidir por nós, de modo a poder culpá-lo do que venha a fracassar. Neste aspecto, o ressentido pode ser tomado como um paradigma do neurótico, com sua servidão inconsciente e sua impossibilidade de implicar-se como sujeito do desejo. (2004, p. 11).

É claro que não há neurótico para além do mundo burguês. Freud bem o sabia ao apontar a necessidade de submissão experimentada pela burguesia, sempre obrigada a obedecer a rígidos princípios morais que sedimentaram a experiência civilizatória. Esta situação de obediência imposta deflagra no sujeito duas ações punitivas: uma destinada ao outro, em forma de sadismo e outra destinada a si mesmo, sob a forma do masoquismo. Não gratuitamente, um romance como O Estranho caso de Dr. Jekyll e Mr. Hyde ${ }^{4}$ só poderia ter sido criado no século XIX e ambientado numa Londres vitoriana. A verdade é que, aos olhos da psicanálise, a história de uma suposta unidade que se surpreende dividida entre o bem e o mal não é tão ficcional assim.

Equilibrando-se em sua precária condição pequeno-burguesa, Lúcia tenta manter sob controle, e longe do olhar dos outros, o casamento bélico que divide com um marido a quem verdadeiramente julga imprestável. De fato, "uma das condições centrais do ressentimento é que o sujeito estabeleça uma relação de dependência infantil com o outro, supostamente poderoso" (KEHL, 2004, p. 14) e a quem caberia a proteção do ressentido. Por isso, a porteira incomoda-se com a intromissão dos vizinhos, preocupa-se com aquilo que supõe ser o senso comum e tenta, tacanhamente, justificar a inutilidade de um parceiro a quem falta todo o tipo de serventia:

A vida pareceu-lhe completamente absurda, como se todos se tivessem combinado para lhe arrancarem metade do corpo. [...] Que ideia triste aquela de assistente social dizer que uma mulher é um ser completo. [...] E quem atarraxava as lâmpadas no tecto? Quem tinha força para empurrar os móveis? Quem espantava os ladrões de carros com dois tiros para o ar, do alto da varanda? Quem desarmava a cama, empurrava o frigorífico, consertava o carro quando avariava, reclamava o criado com voz grossa quando saíam a comer caracóis à beira-mar? Quem enfrentava os policias quando na estrada faziam paragem? Quem conduzia e percebia as coisas do carburador? Quem? Quem? Que papel imprescindível, que pessoa necessária na vida da porteira. ( $M$, p. 489)

Ao repetir "quem?" por tão longo período, Lúcia parece demonstrar que o marido não é mesmo resposta possível a nenhuma de suas indagações. No entanto, a porteira tem muitas perguntas, pois só isto é capaz de explicar as sucessivas justificativas entabuladas por uma fala

\footnotetext{
${ }^{4}$ Romance do escritor escocês Robert Stevenson, publicado em 1886. O livro foi inúmeras vezes adaptado para o cinema, possuindo hoje um farto número de outras releituras feitas pelos quadrinhos, pelo desenho animado e por séries televisivas.
} 
obsessiva que, por ironia, está apartada da presença concreta de interlocutores, excetuando, é claro, a "sua" Regina:

Pensou como, para além do sacramento, seria triste a vida da porteira sem um marido que viesse da oficina-auto com o seu fato-macaco por tratar. Com quem ralharia, por quem iria ao talho, de quem falaria quando fosse às compras, para quem pediria protecção quando cantasse à janela por Salve Regina, a quem pertenceria quando os domingos viessem, e cada mulher saísse com seu homem, se ela nem mais teria o seu. A vida pareceu-lhe completamente absurda. (M, p. 489)

Casada com um homem que fez de seu "fato-macaco" uma segunda pele, reificado pela ausência de nome e pelos "olhos cheios do brilho do vidro" ( $M$, p. 486) - brilho oriundo das garrafas de vinho que pela vida bebeu —, esta mulher não tem com quem contar, firmando-se como um exemplo de isolamento intransponível. De fato, a solidão que envolve a existência feminina é imensa. A porteira é refém de seu ressentimento, num apartamento povoado por gaiolas, marcado por uma iluminação sombria, localizado no último andar de um prédio, "no alto do grande mundo da madrugada" (M. p. 487). Habituada a controlar a voz ("ela canta baixo, às vezes só move os lábios à janela para não atrair a ira dos inquilinos" $-M$, p. 487), e mais engaiolada do que as próprias pombas que o marido aprisiona, a porteira luta por manter o seu "espírito santo", dirigindo suas orações à Regina. Confinada, abandonada e à espera, Lúcia perverte a língua na tentativa de expressar a sua dor:

Salve Regina, mater misericordiae, vita, dulcedo, spes, imensa doçura, salva e vem. Vem e abafa a vida, a roupa, a sala e o fogão, abafa a espera com teu doce bafo. Ampara a vela, acende o fósforo, concentra o ar, protege o som da ira dos inquilinos até ele tocar. Esconde-te invisível, acocora-te, vita, advocata, mãe suprema, minha Regina. Para que não me deslargues, não desesperes, não me desconfines ${ }^{5}$. Por que esperas? (M, p. 485)

A Salve Rainha é o texto sobre qual Lúcia inscreve a sua rasura, uma rasura que lhe expõe o ódio dissimulado, a dor claustrofóbica e um irascível desejo de vingança. Ao suplicar proteção para o marido, o que a porteira constrói é um discurso que anseia por desastres e perigos, aqueles mesmos que, concretamente, jamais acometeriam um simplório mecânico de automóveis. Os improváveis perigos imaginados por Lúcia dão forma a um discurso enviesado, que não consegue esconder o desejo de aniquilamento daquele que a faz sofrer:

\footnotetext{
${ }^{5}$ Grifos meus.
} 
Claro que ele precisa de protecção, antes, depois e durante, porque sempre se está em perigo numa oficina-auto. Imenso perigo porque tem ele de se deitar sob carros inteiros e peças resvaladiças, o corpo completo no chão, a cabeça sob motores, os olhos sob as alavancas mais perigosas [...] o marido da porteira tem um vinho erecto, porque quanto mais toma mais perfila as pernas, a coluna e o corpo todo. O que em princípio deveria não constituir um perigo, mas constitui. Com as pernas desse modo esticadas, fica sujeito a bater com a cabeça numa esquina, a encalhar num lancil, a esfacelar um braço, a ir de encontro a um carro e ser atropelado. [...]. Imaginar a cara do marido sob uma roda em andamento provoca uma angústia vespertina na porteira. ( $M$, p. 485-486)

Diante de tanto sofrimento, Lúcia só pode contar com aquela capaz de se apiedar dos "degredados filhos de Eva", daqueles que estão distantes de Deus, dependentes de sua misericórdia e à espera da atenção divina. Se no princípio, Deus era o verbo, Maria sempre foi linguagem, por isso como a oração alerta, somente através desta "advogada nossa" é que poderemos nos tornar "dignos" das "promessas de Cristo". Se no conto, Regina ganha uma expressão quase humanizada, misto de confidente e de amiga, com quem Lúcia divide a sua solidão; a Virgem, dentro do imaginário cultural do Ocidente, representa o sucesso de uma criação socioideológica que permitiu enquadrar, conter, enfim, evangelizar, a memória pagã das antigas deusas. Porém, como se sabe, o sagrado só se estabelece "na desordem", aquela que faz urgir uma "outra" ordem. Neste sentido, o culto mariano sagrou o lugar da exclusão para todas as formas (des)ordenadas de feminino, o que significa dizer que, a partir de então, entre a Ave e a Eva deixou de haver existência possível. Contudo, não se pode esquecer que a Virgem, a "mater dolorosa”, guarda em si uma pitada de masoquismo, pois será ela quem assistirá de perto à castração e à mortalidade do masculino encarnado pelo Filho. Cabe então a pergunta: o que fez esta mãe para salvar Jesus? Obedeceu, silenciou, resignou-se e o viu morrer, enfim, um conjunto de ações que Lúcia não suportava mais conjugar.

Como um anjo caído e, pela primeira vez, fazendo valer a potência diabólica inscrita em seu nome, Lúcia resolve ir à busca de uma luz que lhe fosse própria, uma luz capaz de suplantar a fragilidade das velas que inutilmente usava para iluminar sua escura realidade. Exausta e vencida por todo um status quo - seja ele representado pelo médico, pelo advogado ou pela assistente social que lhe batiam à porta - ela clama por sua verdadeira salvação: "Salvem-na deste mundo, levem-na no escuro, tratem-na com doçura enquanto se esconde" ( $M$, p. 487).

A mudança operada na personagem está intimamente ligada ao fato de não lhe ser mais possível manter a ficção criada para sua vida, posta a descoberto no momento em que as instituições do poder vêm ao seu encontro, devolvendo-lhe a sua condição de mulher 
"violentada" por um casamento falido. Acuada entre o poder marital — "Isto é, um homem é um homem e um sacramento ainda é mais do que um homem porque esse é uma liga entre dois e nem parte dele perece na Terra" $(M$, p. 488) —, e o das instituições sociais que lhe exigiam um posicionamento, "a porteira entendeu que se haviam congregado todos contra o seu homem e perdeu a doçura, nesse dia mesmo" ( $M$, p. 488).

Abandonando de vez o lugar de vítima enclausurada pela cadeia do ressentimento, Lúcia “perdeu a doçura sem o mostrar" ( $M$, p. 488), intuindo "que uma mulher [nunca seria] um ser completo" se presa estivesse a um lugar de submissão social como era aquele que a sua estreita vida lhe permitiu ocupar. Lúcia decide inverter o jogo da dominação, diabolicamente, resolve "lançar mão do último recurso que distingue o humano do animal: a capacidade de escolher a própria morte" (KEHL, 2004, p. 15), criando para si uma saída que a colocaria, ainda que às avessas, ao lado de Regina:

Ela pede. Vai pedir. E a Regina se ergue, poisa, desce sobre a casa, cada dia uma vitória do céu sobre a terra, do espiritual sobre o mundo, a porteira sabe, nunca dará um passo para se separar do marido. Pensando nisso, chega a sentir um sentimento incristão. Apetece-lhe cuspir contra o conluio dessa gente [...]. Esse sentimento diante da vela é tão esclarecido que ela experimenta uma nova coragem. E como se de repente sentisse uma força sobre-humana vir de dentro dela, sem precisar do auxílio da própria Regina. Está sentada, está esperando, vai ficar assim, cheia de força, sozinha, aguardando as cinco, as seis e as sete. (...) E assim, chegue ele quando chegar, ela estará numa espécie de paz. Ninguém ouvirá, ninguém correrá persianas pela sua chegada, ninguém mais se meterá na sua vida. Que mudança! ( $M$, p. 490-491)

A "mudança", oriunda de um "sentimento incristão" dá à Lúcia uma "força sobrehumana" que a faz dispensar o "auxílio da própria Regina". O conto aqui inicia um segundo movimento que acompanha a transformação da personagem, agora munida de "uma nova coragem”. A porteira liberta-se da opressão do tempo que, até então, era medido através do relógio que marcava a espera pela chegada do marido. Surpresa, Lúcia percebe que o tempo que regia a paralisia de seus dias deixa de existir e conclui: "devem ter-se avariado todos os relógios, porque [o tempo] passou sem dar por passar" ( $M$, p. 491). "Mesmo sem Regina" ( $M$, p. 491) e com a ameaçadora chama da vela acesa pelo seu homem diante de si, ela não "produzirá uma única palavra", pois nem marido, nem instituições serão agora capazes de evitar sua "consagração". Diante do fogo assassino, Lúcia repete obstinada: "não a demoveram" ( $M, \mathrm{p}$. 492). 
E assim, "ele toma a vela, traz a vela, traz a vela do Rex e da Regina até junto da porteira, puxa-lhe a roupa, aproxima a vela da camisa de nylon, com brilho e em silêncio. Ateia. Ateou? Ateou a camisa?" ( $M$, p. 492). Criando um jogo fônico entre "ateia" e "atéia", a narrativa parece deixar margem para que uma outra forma de assunção aconteça, consagrando de maneira herege a escolha da morte "como meio de preservar a humanidade", pois, "morrer, ou deixar-se matar é a afirmação extrema de insubmissão sob regimes totalitários” (KEHL, 2004, p. 15).

A porteira, ao abrir as portas para outra possibilidade de existência, liberta-se de sua realidade opressora e hereticamente concretiza a sua vingança, abandonando de vez a inação que acompanha os ressentidos. Assumindo para si a danação como destino, ela desce os corredores em chamas, para só parar "na porta do advogado do quinto", número emblemático que retoma "um quinto dos infernos" propositadamente ansiado por um corpo feminino que "crepita" à espera de uma estranha forma de assunção:

Só no quinto a chama da porteira pára. Crepita. É a porta do advogado do quinto. Sem barulho, fica à porta do advogado, das testemunhas e da lei. A Regina assim quer que fique. Regina acocorada sobre ela, no quinto, de asas abertas sobre o quinto, e o marido no décimo. (...). Abre as asas, advocata, levanta vôo, leva a porteira, condu-la na maca, ergue-lhe a vista. Regina, separa-a definitivamente da cama, do balde e do fogão. Separa-a dos dez andares que o prédio tem, separa agora, et nunc, et sempre, et séculos. ( $M$, p. 492)

Levada por Regina deste vale de lágrimas, a porteira é conduzida "sem ruído, sem sirene, sem apito, sem camisa, sem cabelo, sem pele” ( $M$, p. 492), carne exposta que fere o olhar do leitor surpreendido diante de tamanho horror, ao mesmo tempo em que lhe reativa a origem etimológica do termo "crueldade"6. Considero que, mais do que partir de uma referencialidade histórica para discutir a condição feminina neste novo milênio, este conto de Lidia Jorge é um exemplo primoroso daquilo que, em $O$ retorno do real (1996), Hal Foster chamou de "realismo traumático". Uma forma de recriação que se vale de um bem engendrado conjunto de imagens que, "na derrota representativa diante do real, refletem a repetição e a compulsão de repetição desse encontro fracassado com o real irrepresentável” (SCHOLLHAMMER, 2012, p. 140).

\footnotetext{
${ }^{6}$ Cito: "Cruor, de onde deriva crudelis (cruel) assim como crudus (cru, não digerido, indigesto) designa a carne escorchada e ensanguentada: ou seja, a coisa mesma privada de seus ornamentos ordinários” (ROSSET, 2002, p. 1718).
} 
Por crer que o real só pode ser traumaticamente representado, ou antes, enviesadamente recriado, é que me permito ver neste conto não a história de uma mulher vencida pela violência, mas sim a narrativa da vitória do feminino que usou o ódio para diabolicamente não se deixar vencer. De resto, é sempre bom lembrar que as existências de medeias, joanas e lúcias são provas irrefutáveis de que a boa ficção sempre preferiu a inquietante sedução do inferno, ao sossego prometido pelo paraíso sempre tão previsível.

\section{Referências}

CLEMENT, Catherine \& KRISTEVA, Julia. O feminino e o sagrado. Rio de Janeiro: Rocco Editora, 2001.

FOSTER, Hal. O retorno do real. A vanguarda no final do século XX. Rio de Janeiro: Cosac Naify, 1996.

GONÇALVES, Maria Madalena. "Lídia Jorge: a arte de narrar Marido e outros contos". In: Revista Românica 9. Lisboa: Edições Colibri, 2000, p. 123-138.

HOLANDA, Chico Buarque de \& PONTES, Paulo. Gota d'água. São Paulo: Círculo do Livro, 1975.

. "Marido". In: Melo, João de (org.). Antologia do conto português. Lisboa: Publicações D. Quixote, 2002, p. 483-492.

JORGE, Marido e outros contos. Lisboa: Publicações D. Quixote, 1997.

KEHL, Maria Rita. Ressentimento. São Paulo: Caso do Psicólogo, 2004.

ROSSET, Clément. O princípio da crueldade. Rio de Janeiro: Rocco, 2002.

SCHOLLHAMMER, K. E. "Do efeito ao afeto. Os caminhos do realismo performático". In: MARGATO, I. \& GOMES, R. C. (orgs.). Novos Realismos. Belo Horizonte: Editora UFMG, 2012, p. 133-146. 